\title{
WHAT ARE THE ASPECTS OF ADOPTING COMPUTER-BASED EXAMS AND DO THEY IMPACT NEGATIVELY ON STUDENTS?
}

\author{
Rabea Emdas ${ }^{1}$ and Ahmed Alruwaili ${ }^{2}$ \\ ${ }^{1}$ Faculty of Science, Engineering and Technology, Swinburne University \\ of Technology, Hawthorn, Victoria 3122, Australia \\ ${ }^{2}$ Department of Computer Science and Information Technology, \\ La Trobe University, Bundoora, Victoria 3086, Australia
}

\begin{abstract}
Computer-based exams (CBEs) have been used in various courses, such as schools, universities and other training centres. As there are many educational institutions which have chosen to convert from paper test system to computer- based exam. However, adopting computer tests may lead to some difficulties for the students, which relates to technical defects and lake of computer skills of some students when they applying the computer based exams. The purpose of the essay was to determine negative and positive effects on the students of using computer-based exams and focus on some of suggesting solutions to the negative effects, such the exams to make continuous use of computer-based possible. In the first section the computer test, which could cause negative effects on students due to various levels of skills to use computer and some technical problems was examined. The design of the computer examination system requires careful planning and study from several aspects before becoming officially accepted, the computer-based exams still have a few problems which may lead to difficulties in using computer exams. Then the many benefits which could be gained by using computer-based exams, such as the student will be more independent with computer test were described. In addition, the students have accessible to the exams through the internet network. Finally, the effectiveness of certain strategy to solve the negative effects of computer-based exams were argued. developing the solutions of the technical problems are required for computer test, where improving the input methods questions and corrections. It was concluded that the computer exam, with adjustments, is more suitable for students.
\end{abstract}

\section{KEYWORDS}

Computer-Based Exams, Computer test, computer system examinations, computer test model.

\section{INTRODUCTION}

The computer-based exam is a system designed for the students' to do exams via computer. Therefore, electronic devices which are providing developed software has changed to be more suitable in educational operation $[1,2]$. All these developments of the schooling devices have made it possible for students to do computer tests with better performance. On the other hand, adopting computer tests may lead to some difficulties for the student, which is related to technical defects and computer skills when applying the computer-based exam. These difficulties prevent the application of the computer test easily. For example, unequal levels of computer skills among the users could be a barrier to apply this kind of test equally. In addition, technical problems that are related to hardware and software are considered as one of the practical problems [3-5]. 
However, there are some advantages for the computer-based exam compared with the paper tests and that represented in easy access and accuracy of the assessment of the questions. As a result, the students become more independent in the study, due to the student not receiving help from anyone. This essay will discuss negative and positive effects on the students when the computerbased exams been used and focus on suggesting some solutions to the negative effects of such exams to make continuous use of the computer based exams possible $[6,7]$.

\section{BACKGROUND}

Computer-based exams (CBEs) are software of computer that support test papers to present electronically. According to Bennett, Braswell, Oranje, Sandene, Kaplan and Yan [6], electronic tests are powered by a database containing all the subjects' data of the student. In addition, electronic tests have function which are correcting the questions accurate and showing individual results for each question. According to Goldberg and Pedulla [5], computer-based exams are supported the materials and topics differently, such as questions of mathematics test would use many functions more than history questions. The test which is done by the computer includes questions that are connected by database. Therefore, computer-based tests might have less error than the paper examinations. The computer exam is highly bases on the new technology, in order to accurately assess the performance of the students during the exam. For example, supporting of the new functions and developed versions of the software were used in the exam $[8,9]$. The electronic system test is designed to be done by computer which is provided with many options. For example, the computer test could have direct messages which can displayed as a result for each question [7]. In addition, the exam which using the computer based is more accessible for students even through the internet, while the paper examination could not support like this option $[7,10]$.

\section{The Negative ImPaCts of The Electronic Test ON Students}

The use of computer tests may have significant negative impacts on the student when the student is doing computer exams. According to Frankel, Altschuler, George, Kinsman, Jimison, Robertson and Hsu [11], the computer-based exam has a high accuracy when calculate the errors of the students during the exams. Consequently, lack of computer skills might have a negative impact on students when doing the computer-based exams, because of the concentrating of student to answer questions and how to use the computer. However, the computer test is accreted and gives the specific time to the student for reviewing errors during the examination, while in the paper exam could not deal with time accurately same as and cheque errors. Table 1 depicts elements of the Input- Skill for the student, focusing on accuracy and speed [6].As can be seen from Table 1, accuracy skills are 17 maximum points. While the speed skills are 22 points, which cloud means that the students may already release some of his errors after he knew the calculation marks in the computer test. Therefore, the problems of computer exams could hinder the student to continuing in the exam, which may impact on the student's performance. Due to of these similar problems the concentrating of the student could really be shifted from answering questions to technical problems. Shacham [1] stated that the computer problems which are related to hardware and software could affect on the performance of student, which is possibly making the student return the exam from beginning. These two major areas of problem might be negatively affecting the level of student performance $[7,12]$.

\section{The Positive Effects of the Electronic Test on Students}

Using computer-based exams could have a positive effect on students, due to electronic tests provide many options for the students which were not available in the paper examinations. 
However, the electronic test system focuses on the time factor and quick access to records. The computer test system is provided on electronic records that are different from paper records [1, 10]. In addition, these kinds of questions could include multiple choices for the student, such as inputting maths expressions and numerical answers. Moreover, the computer-based exam calculates the time of the test accurately, and displays student's mistakes at the same time. The questions show on the screen sequentially. As a result, the students could understand each question individually. Computer Based Exams (CBEs) have been used in various courses $[1,2]$. In such tests, all the questions are answered via individual interactive work with a personal computer. Immediate feedback on errors is provided and the rating is typically done by the computer. The time frame of the computer-based exams could be set so that the largest number of students able to redo the exam. There is no assistance to the student from anyone, which could make the student more independent. This means that the student would take responsibility for study [3]. In addition, the computer-based exam supports simulation tests for some special applications, such as computer and physics experiments. This means that the computer test can be used to simulate some practical experiments which are requiring high cost and hardware. Thus, the students can obtain a hands-on experience before commencing to do some real exam. All these steps could assist to increase the student's performance [4].

Table 1. Elements of the Input- Skill

\begin{tabular}{|c|c|c|c|}
\hline Variable Accuracy & Max. Points & Variable Speed & Max. Points \\
\hline Typing and editing & & Typing and editing & \\
\hline $\begin{array}{l}\text { Accuracy typing a brief given } \\
\text { passage }\end{array}$ & 2 & Time to type a brief passage & 2 \\
\hline Accuracy inserting a word & 2 & Time to insert word & 2 \\
\hline Accuracy changing a word & 2 & Time to change word & 3 \\
\hline Navigating the test & & Navigating the test & \\
\hline $\begin{array}{l}\text { Accuracy pointing and mouse } \\
\text { clicking }\end{array}$ & 2 & Time to point and click & 3 \\
\hline Accuracy scrolling & 2 & Time to scroll & 2 \\
\hline $\begin{array}{l}\text { Accuracy clicking on the } \\
\text { "Next" icon }\end{array}$ & 2 & Time to click on "Next" & 3 \\
\hline $\begin{array}{l}\text { Accuracy clicking on the } \\
\text { "Previous" icon }\end{array}$ & 2 & Time to click on "Previous" & 2 \\
\hline Entering responses & & Entering responses & \\
\hline $\begin{array}{l}\text { Accuracy filling in a mixed } \\
\text { number }\end{array}$ & 2 & Time to fill in mixed number & 2 \\
\hline Using the calculator & & Using the calculator & \\
\hline $\begin{array}{l}\text { Accuracy in performing a } \\
\text { given operation }\end{array}$ & 1 & $\begin{array}{l}\text { Total time to complete the } \\
\text { calculator tutorial }\end{array}$ & 3 \\
\hline Total Of Accuracy & 17 & Total Of Speed & 22 \\
\hline
\end{tabular}

\section{The Strategies to Solve the Negative Effects of Computer - BASED EXAM SYSTEMS}

The electronic test system may have a few errors as does any system which is built to solve a problem or develop the old system. The computer-based exam system is relatively recent compared with the paper examination system. According to Shacham [1] the computer based exams require extra development to support multiple functions and some tools. Therefore, the computer test should be more suitable to the students. For example, voice technology is the 
technique used in some international tests, such as the TOEFL exam, which gives the student a chance to display conversation skills. All these improvements in the computer system test could have a positive effect on the students whom would increase their performance. According to Mary [3] solving of technical problems can be caused to develop computer test for example, improve the input method of questions and corrections, which should make the computer exam more simple for the students. Taking into account the student's needs considering the sensitive issue of the technical problems in the computer test, which could affect skills of the students more than traditional exams. Such as the rebooting computer system for various reasons which often leads to wasting time and causes frustration. This complaint of students about computer exams is related to the technical problems, these two major strategies could solve problems of the computer test.

\section{Conclusions}

Design of the computer examination system requires a lot of planning and study from several aspects before becoming certified. Using electronic tests may have benefits to students. On the other hand, the computer-based test still has a few problems; these problems may lead to difficulties in using computer tests, such as technical problems and computer skills. As a result, the student should have sufficient time to gain good experience in using computer tests, where this test system focuses on the time factor and quick access to records, the computer- based exams calculate the time of the test accurately. Therefore, the test could assist performance of student, which make test more suitable for the students, such as input method questions and corrections, and using technology by various ways, where is making the computer-based exam support voice input, editing texts and easily update. However, technical problems with the hardware could be decreased by using new and well-maintained computers. It is expected that with the increase of using the computer-based exam at educational institutes, while the using of the paper examination may decrease.

\section{ACKNOWLEDGEMENTS}

The authors would like to thank Dr Abd Alhamid R. Sarhan (Faculty of Science Engineering and Technology - Swinburne University of Technology) for his support.

\section{REFERENCES}

[1] Shacham, M.: 'Computer-based exams in undergraduate engineering courses', Computer Applications in Engineering Education, 1998, 6, (3), pp. 201-209.

[2] Wingenbach, G.J.: 'Agriculture Students' Skills and Electronic Exams', Journal of Agricultural Education, 2000, 41, (1), pp. 69-78.

[3] Mary, P.: 'The Effect of Using Item Parameters Calibrated from Paper Administrations in Computer Adaptive Test Administrations', The Journal of Technology, Learning and Assessment, 2007, 5, (7).

[4] Blumenstein, M.: 'Synergies of Learning Analytics and Learning Design: A Systematic Review of Student Outcomes', Journal of Learning Analytics, 2020, 7, (3), pp. 13-32.

[5] Goldberg, A.L., and Pedulla, J.J.: 'Performance Differences According to Test Mode and Computer Familiarity on a Practice Graduate Record Exam', Educational and Psychological Measurement, 2016, 62, (6), pp. 1053-1067.

[6] Randy Elliot, B., James, B., Andreas, O., Brent, S., Bruce, K., and Fred, Y.: 'Does it Matter if I Take My Mathematics Test on Computer? A Second Empirical Study of Mode Effects in NAEP', The Journal of Technology, Learning and Assessment, 2008, 6, (9).

[7] Zilles, C., West, M., Mussulman, D., and Bretl, T.: 'Making testing less trying: Lessons learned from operating a Computer-Based Testing Facility', in Editor (Eds.): 'Book Making testing less trying: Lessons learned from operating a Computer-Based Testing Facility’ (IEEE,2018, edn.), pp. 1-9. 
[8] Morrison, B.B., Margulieux, L.E., Ericson, B., and Guzdial, M.: 'Subgoals help students solve Parsons problems', in Editor: 'Book Subgoals help students solve Parsons problems' (2016,edn.), pp. 42-47.

[9] Zilles, C., Deloatch, R.T., Bailey, J., Khattar, B.B., Fagen, W., Heeren, C., Mussulman, D., and West, M.: 'Computerized testing: A vision and initial experiences', age, 2015, 26, pp.1.

[10] Hainey, T., Connolly, T.M., Boyle, E.A., Wilson, A., and Razak, A.: 'A systematic literature review of games-based learning empirical evidence in primary education', Computers \& Education, 2016, 102, pp. 202-223.

[11] Frankel, R., Altschuler, A., George, S., Kinsman, J., Jimison, H., Robertson, N.R., and Hsu, J.: 'Effects of exam-room computing on clinician-patient communication: a longitudinal qualitativestudy', J Gen Intern Med, 2005, 20, (8), pp. 677-682.

[12] Zilles, C.B., West, M., Herman, G.L., and Bretl, T.: 'Every University Should Have a ComputerBased Testing Facility', in Editor (Eds.): 'Book Every University Should Have a Computer-Based Testing Facility’ (2019, edn.), pp. 414-420.

(C) 2021 By AIRCC Publishing Corporation. This article is published under the Creative Commons Attribution (CC BY) license. 